\title{
Türkiye ve Almanya-Hamburg Hayat Bilgisi Dersinin Karşılaştırılması: Genel Bir Bakış
}

\section{Comparison of Life Science Courses in Turkey and Germany- Hamburg: A General Outlook}

\author{
Z. Nurdan BAYSAL ${ }^{* *}$ Özlem TEZCAN ${ }^{* * *} \quad$ K. Ersin ARAÇ ${ }^{* * * * *}$
}

Received: 08 December 2016

Accepted: 08 January 2018

\begin{abstract}
The purpose of this study is to compare the current curricula of the life science courses implemented in Turkey and Germany-Hamburg to reveal the similarities and differences between them. Germany-Hamburg was chosen for comparison because the life science course, which is called social sciences course in many countries, taught there has a similar structure to the one taught in Turkey. The common aspects of these two countries make the conclusion more meaningful. Literature review was conducted first to determine the relevant criteria for the comparison between the two countries. In this way, the official documents of both countries were reviewed. Survey method, which is a qualitative research method, was used, and horizontal approach and descriptive approach, which are among comparative educational approaches, were employed. Based on the obtained data, the similarities and differences between the countries were identified with regard to school starting age and compulsory education structure, educational administration and financing, school choice, dress and educational support, the goals of elementary school, the courses taught, and assessment and evaluation. Then the curricula implemented in the two countries were compared in terms of acceptance date, course content, mission/vision, the prescribed skills or competencies, and assessment and evaluation.
\end{abstract}

Keywords: life science course, comparative education, Turkey, Germany-Hamburg.

ÖZ: Bu araştırmanın amacı; Türkiye ve Almanya-Hamburg eyaletinde okutulmakta olan Hayat Bilgisi dersinin güncel programlarını karşılaştırarak benzerlik ve farklılıklarını ortaya koymaktır. Birçok ülkede Sosyal Bilgiler olarak adlandırılan Hayat Bilgisi dersinin her iki ülkede de benzer yapıda bir ders olması açısından AlmanyaHamburg seçilmiştir. Araştırmada nitel araştırma modellerinden tarama modeli, karşılaştırmalı eğitim yaklaşımlarından "yatay yaklaşım" ve "tanımlayıcı yaklaşım” kullanılmıştır. Elde edilen verilerle öncelikle her iki ülkede, okula başlama yaşı ve zorunlu eğitim yapısı, eğitim yönetimi ve finansmanları, okul seçimi, kıyafet ve eğitim desteği, ilkokulun amaçları, okutulan dersler, ölçme ve değerlendirme arasındaki benzerlik ve farkl1lıklar belirlenmiştir. Daha sonra her iki ülkenin Hayat Bilgisi güncel programlarının kabul tarihi, ders içeriği, amaç/vizyonu, kazandırılması öngörülen beceriler ve ölçme değerlendirme yaklaşımları karşılaştırılmıştır. Bulgular 1şığında her iki ülkede de ilkokul basamağına başlama yaşı, zorunlu eğitim yapısı, okul seçimi ve kıyafet yönetmeliği konusunda benzer, eğitim yönetimi ve finansman açısından farklı uygulamalar yapıldığı söylenebilir. Hayat Bilgisi dersinin yapısı incelendiğinde ise haftalık ders saati, dersin amaçları, kazandırmayı hedeflediği beceriler ve ölçme değerlendirme açısından benzer ve farklı yönler bulunduğu belirlenmiştir.

Anahtar kelimeler: hayat bilgisi, karşılaştırmalı Eğitim, Türkiye, Almanya-Hamburg.

*11-14 Mayıs 2016 tarihleri arasında düzenlenen XV. Uluslararası Katılımlı Sınıf Öğretmenliği Eğitimi Sempozyumu'nda sözlü bildiri olarak sunulmuştur.

** Assoc. Prof. Dr., Marmara University, İstanbul, Turkey, znbaysal@ marmara.edu.tr

${ }^{* * *}$ Corresponding Author: Res. Asst. Dr., Kocaeli University, Kocaeli, Turkey, ozlem.apak@ hotmail.com

${ }^{* * * *}$ Teacher, Tuzla Doğa College, Istanbul, Turkey, kamilersinarac@ gmail.com

Citation Information

Baysal, Z. N., Tezcan, Ö., \& Araç, K. E. (2018). Türkiye ve Almanya-Hamburg hayat bilgisi dersinin karşıllaştırılması: Genel bir bakış. Kuramsal Eğitimbilim Dergisi [Journal of Theoretical Educational Science], 11(1), 117-134. 


\section{Giriş}

Hayat Bilgisi dersinin başlangıcı ile ilgili kesin bir tarih vermek zor olmakla birlikte, düşünce temelinin, öğrencinin mümkün olduğunca eşyaya yaklaştırılması, eşyayı gözlemlemesi ve kullanması gerektiği görüşünü ileri süren Eflatun'a kadar dayandığı söylenebilir. Hayat Bilgisi dersinin kurucusu, çocuklar için "Gözle Görülen Resimli Dünya" adlı ilk resimli kitabı yazan Johann Amos Comenius (1592- 1670) olduğu kabul edilmektedir. Bu kitap ile Comenius ilkokullarda Hayat Bilgisi dersine ilk sınıflar için en uygun şeklini vermiş ve yaşamın bir bütün olarak ele alınması gerektiğini ileri sürmüştür (Sağlam, 2015). Günümüze gelinceye kadar Hayat Bilgisi dersi için önemli gelişmeler söz konusu olmuştur.

Türkiye'de 30 Mart 2012 tarih, 6287 sayılı İlköğretim ve Eğitim Kanunu ile Bazı Kanunlarda Değişiklik Yapılmasına Dair Kanun ile 4+4+4 olarak bilinen kesintisiz ve zorunlu eğitime geçiş yapılmıştır. İlköğretim basamağının 2 kademeye ayrılması ve 5. sınıfın ilkokuldan alınarak ortaokullara bağlanması ile birlikte ilkokul eğitimi 4 yıla indirilmiştir. Öğrenim yılı dışında ders listeleri revize edilmiş ve bir takım düzenlemeler yapılmıştır. Bu düzenlemelere göre 1, 2. ve 3. sınıfta okutulan Hayat Bilgisi dersi 4 ve 5. sınıfta fen ve teknoloji dersi ile Sosyal Bilgiler dersine temel oluşturmaktaydi. Yeni yapılan düzenleme ile Sosyal Bilgiler ve Fen Bilimleri olarak isimleri güncellenen derslerin haftalık saatleri Tablo 1'de görüldüğü şekildedir.

Tablo 1

Hayat Bilgisi, Sosyal Bilgiler, Fen Bilimleri ve İnsan Haklarl, Yurttaşlık ve Demokrasi Dersleri Haftalı Ders Saatleri

\begin{tabular}{lcccc} 
& 1. Sınıf & 2. Sinıf & 3. Sınıf & 4. Sınıf \\
\hline Hayat Bilgisi & 4 & 4 & 3 & - \\
\hline Sosyal Bilgiler & - & - & - & 3 \\
\hline Fen Bilimleri & - & - & 3 & 3 \\
\hline İnsan Hakları, Yurttaşlık ve Demokrasi & - & - & - & 2 \\
\hline
\end{tabular}

Uyarlandiğı yayın. MEB (2015) Ders Çizelgesi

Tablo 1'de görülen düzenlemeler ile birlikte bu derslerin içeriklerinde de düzenlemeler söz konusu olmuştur. Dolayısıyla 29.07.2015 tarihli 60 sayılı "İlkokul Hayat Bilgisi Dersi (1, 2 ve 3. Sınıflar) Öğretim Programı” kurul kararı ile değişikliğe uğramış ve önceki programın 2016-2017 eğitim ve öğretim yılından itibaren 1 . sınıflardan başlamak üzere kademeli olarak uygulamadan kaldırılmasına karar verilmiştir (MEB, 2015). Bütün bu değişikliklerle birlikte Ülkemizde, Cumhuriyetin ilk yıllarından beri uygulanan Hayat Bilgisi Öğretimi Programı'na isim, desen ve içerik yönünden benzeyen program yalnızca Almanya'da "Sachunterricht" ismiyle yer almaktadır. Karşılaştırmalı eğitim kapsamında incelendiğinde Almanya ve Türkiye dışında diğer ülkelerde Hayat Bilgisi dersine karşılık gelen farklı ders isimleri ile farklı ders veya dersler de verilmektedir.

Karşılaştırmalı eğitimin amaçlarından birisi eğitimsel olguların daha iyi anlaşılmasını sağlamaktır. Karşılaştırmalı bir çalışmanın bilimsel hedefi ne olursa olsun, 
araştırmacı hemen hemen her zaman, önerilen çözümlerin muhtemel sonuçlarını öngörebilmek ve eğitimi en iyi duruma ulaştırabilmek için bir takım eğitimsel olgu ve olayları daha iyi anlama peşindedir. Karşılaştırmalı çalışmaların çoğu, aslında eğitim ve öğretimi iyileştirme girişimidir. Örneğin, OECD, Dünya Bankası, UNESCO ve AB gibi kurumların karşılaştırmalı eğitim çalışmalarının temel amacı eğitimi geliştirmektir (Uygun, Ergen \& Öztürk, 2011).

Ayrıca karşılaştırmalı eğitim çalışmaları eğitim sorunlarının çözümünde başka ülkelerin tecrübelerinden yararlanma imkânı sağlamanın yanında, ülkenin kendi eğitim yapısının ve sorunlarının daha iyi anlaşılmasına da yardımcı olabilir. Farklı iki ülkede benzer bir mantıkla hazırlanan Hayat Bilgisi dersini incelemeden önce Türkiye ve Almanya eğitim sistemi ile ilgili kısa bir bilgilendirme yapmak yerinde olacaktır. Bu bilgilendirmede amaç, genel eğitim sistemleri ile ilgili bilgi vermek yanında temel eğitim basamağı ile ilgili esasların aktarılmasını ve Hayat Bilgisi dersi üzerinden yapılacak karşılaştırmanın daha anlaşılır hale gelmesini sağlamaktır.

$\mathrm{Bu}$ araştırmanın amacı, Türkiye ve Almanya-Hamburg eyaletindeki Hayat Bilgisi dersi ile ilgili benzerlik ve farklılıkların ne olduğunu tespit etmektir.

Araştırma soruları şöyle sıralanabilir:

1. Türkiye ve Almanya- Hamburg eyaletinde genel eğitim sistemleri;

1.1. Okula başlama yaşı ve zorunlu eğitim yapısı,

1.2. Eğitim yönetimi ve finansmanlar1,

1.3. Okul seçimi, kıyafet ve eğitim desteği,

1.4. İlkokulun amaçları,

1.5. İlkokuldaki dersler,

1.6. İlkokulda ölçme ve değerlendirme arasındaki benzerlik ve farklılıklar nelerdir?

2. Türkiye ve Almanya- Hamburg eyaletinde okutulan;

2.1. Hayat Bilgisi dersinin tarihsel süreci,

2.2. Hayat Bilgisi dersinin amac1,

2.3. Hayat Bilgisi dersinin yapıs1,

2.4. Hayat Bilgisi dersinin haftalık ders saati,

2.5. Hayat Bilgisi dersinin öğrenme alanları,

2.6. Hayat Bilgisi dersinde kazandırılması hedeflenen beceriler,

2.7. Hayat Bilgisi dersinde ölçme ve değerlendirme açısından benzerlik ve farkl1lıklar nelerdir?

\section{Yöntem}

\section{Araştırmanın Modeli}

Araştırmada nitel araştırma modellerinden tarama modeli, yaklaşım olarak karşılaştırmalı eğitim yaklaşımlarından "yatay yaklaşım” ve "tanımlayıcı yaklaşım" kullanılmıştır. Yatay yaklaşımda eğitim sistemindeki tüm boyutlar ayrı ayrı ele alınmaktadır (Türkoğlu, 1998). Tanımlayıcı yaklaşımda ise ilgili literatür incelenerek benzerlikler ve farklılıklar karşılaştırılmaktadır (Ültanır, 2000). Bu çalışmada da eğitimin genel yapısı ve Hayat Bilgisi dersine yönelik durumlar ayrıntılı olarak ele alınmıştır. Ardından iki ülke açısından karşılaştırılması öngörülen unsurlar, benzerlik ve farklılıklar açısından karşılaştırılmıştır. 


\section{Veri Toplama Araçları}

Araştırmada öncelikle birincil kaynaklar incelenmiştir. Birincil kaynak olarak Türkiye'de "İlkokul Hayat Bilgisi Dersi (1, 2 ve 3. sınıflar) Öğretim Programı” (2013) ile Almanya- Hamburg'da "Bildungsplan Grundschule Sachunterricht Programı" (2011) incelenmiştir. Ayrıca ulusal ve uluslararası düzeyde çalışılan makale, kitap bölümü ve tezler incelenmiş, resmi web sayfalarındaki bilgilerden yararlanılmış ve bu bilgiler, ilgili temalar altında sunulmuştur.

\section{Verilerin Analizi}

Araştırmanın bulguları, doküman analizi yöntemi ile analiz edilmiştir. Öncelikle hangi başlıklarda karşılaştırma yapılacağına yönelik çıkarımda bulunabilmek amacıyla alan yazın taraması yapılmıştır. Daha sonra ilgili dokümanları resmi, orijinal ve güncel kaynaklar olup olmadığı kontrol edilmiştir. En son olarak da dokümanları anlama ve Türkçe'ye çevirme noktasında iki ayrı araştırmacı analizini yapmış, daha sonra bir araya gelerek kontrolü sağlanmıştır. Elde edilen veriler ile her iki ülkenin güncel programlarının kabul tarihi, ders içeriği, amaç/vizyonu, kazandırılması öngörülen beceriler veya yeterlilikler ve ölçme değerlendirme yaklaşımları açılarından değerlendirilerek karşılaştırmalar yapılmıştır. Çalışmada öncelikle Türkiye ve AlmanyaHamburg eğitim sisteminin temel özellikleri incelenmiştir. Daha sonra iki ülkedeki öğretim programları ayrıntılı bir biçimde analiz edilmiştir.

\section{Bulgular}

$\mathrm{Bu}$ bölümde araştırma kapsamında Türkiye ve Almanya- Hamburg eyaletinde genel eğitim sistemleri ve Hayat Bilgisi dersi arasındaki benzerlik ve farklılıklar yer almaktadir.

Türkiye ve Almanya- Hamburg Eyaletinde Genel Eğitim Sistemleri Arasındaki Benzerlik ve Farklılıklar

Okula başlama yaşı ve zorunlu eğitim yapısı. Türkiye'de ilkokulların birinci sınıfına, kayıtların yapıldığı yılın eylül ayı sonu itibarıyla 66 ayını dolduran çocukların kaydı yapılır. Gelişim yönünden ilkokula hazır olduğu anlaşılan 60-66 ay arası çocuklardan, velisinin yazılı isteği bulunanlar da ilkokul birinci sınıfa kaydedilir (Resmi Gazete, 2014, s. 29072). Almanya- Hamburg'da ise çocuk Temmuz ayında 6 yaşını doldurursa, o yılın Ağustos ayından itibaren okula gitmek zorundadır (Beutner \& Medvedev, 2013). Türkiye'de zorunlu eğitim 4+4+4 olarak kesintisiz 12 yıl iken, ilk dört sinıf ilkokulu kapsar (MEB, 2012). Almanya- Hamburg'da 4+5+3 olarak toplam 12 y1ldır (MEB, 2012; Hamburg Eğitim Ataşeliği, 2013).

Eğitim yönetimi ve finansmanları. Türkiye'de Milli Eğitim Bakanlığı'nın bünyesinde bulunan Talim ve Terbiye Kurulunun hazırladığı öğretim programı bütün ülkede uygulanırken, Almanya- Hamburg'da federal eğitim sitemi olduğu için yetki ve sorumluluklar eyalet yönetimine aittir (Beutner \& Medvedev, 2013). Bu duruma bağl1 olarak eğitim finansmanları da Türkiye'de Milli Eğitim Bakanlığg, AlmanyaHamburg'da ise eyalet yönetimleri sağlamaktadır. Federal Almanya Cumhuriyeti'nin eğitim politikasının ve planlamasının sorumluluğu devletin federal yapısı dikkate alınarak belirlenmiştir (Bal \& Başar, 2014; Kasapçopur, 2007; Özmen \& Yasan, 2007). Federal Anayasa ve eyalet yasaları gereğince genel eğitim sistemi devletin gözetimi 
altındadır ve devletin yükümlülüklerini eyaletlere devretmiştir (Kantos, 2013). Bu yüzden eğitim sisteminin yönetimi ve düzenlemesi eyaletlerin sorumluluğundadır. $\mathrm{Bu}$ doğrultuda 16 eyaletten biri olan Hamburg'da da diğer eyaletlerden farklı eğitim uygulamaları yapılmaktadır (Beutner \& Medvedev, 2013). Buna bağlı olarak Hamburg'daki eğitimden sorumlu birim Okul ve Mesleki Eğitim Bakanlığı (Ministry of Schools and Vocational Training) olarak belirlenmiştir (DEQUA-VET, 2016).

Okul seçimi, kıyafet ve eğitim desteği. Türkiye'de Milli Eğitim Bakanlığının yayınladığı İlköğretim Kurumları Yönetmeliğinin 16. maddesinde; “Öğrencilerin Ulusal Adres Veri Tabanında belirtilen ikametgâhlarına en yakın ilköğretim okuluna kaydedilmeleri esastır" ifadesi bulunmaktadır. Bu yönetmelik ile 2009-2010 eğitim öğretim yılından itibaren ülke genelindeki öğrenci kayıtlarının Ulusal Adres Veri Tabanındaki adresler esas alınarak gerçekleştirileceği Milli Eğitim Bakanlığı'nın 2009/30 Sayılı genelgesi ile karara bağlanmıştır (Sincar \& Özbek, 2011). AlmanyaHamburg'da da ikamete dayalı bir devlet okulu ya da isteğe bağlı özel okul seçimi mümkündür. "Kısa bacaklı küçüklere - kısa yol" ilkesinden hareketle anne-babanın tercih hakkı devam ederken ikamete dayalı olarak seçim yapabilirler. Aileler bu çevrenin dişından da -boş yer varsa- bir okul seçebilirler (Hamburg Eğitim Seferberliği, 2009). Yine aynı şekilde iki ülkede de ilkokulda serbest kıyafet yönetmeliği uygulanmasına rağmen bazı okullarda üniforma zorunluluğu bulunmaktadır.

İlkokulun amaçları. Türkiye'de 1739 sayılı Milli Eğitim Temel Kanunu ile ilkokulun amaçları ; "her Türk çocuğuna iyi bir vatandaş olmak için gerekli temel bilgi, beceri, davranış ve alışkanlıkları kazandırmak; onu milli ahlak anlayışına uygun olarak yetiştirmek ve ilgi, istidat ve kabiliyetleri yönünden yetiştirerek hayata ve üst öğrenime hazırlamak" olarak belirlenmiştir (MEB, 1739). Almanya'da ise ilkokulun amaçları; çocukların öğrenme yeteneğini ve iş görme becerisini geliştirmek, çocukların sosyalleşmesini sağlamak ve öğrencileri orta öğretime hazırlamaktır.

İlkokuldaki dersler. Türkiye'de ilkokulda yer alan dersler şunlardır: Türkçe, Hayat Bilgisi (1.,2. ve 3. sinıf), matematik, Fen Bilimleri (3. ve 4. sinıf), sosyal bilimler (4.sınıf), yabancı dil (2., 3. ve 4.sınıf), din kültürü ve ahlak bilgisi (4.sınıf), görsel sanatlar, müzik, oyun ve fiziki etkinlikler, trafik güvenliği (4.sınıf), insan hakları, yurttaşlık ve demokrasi (4.sınıf), serbest etkinlikler (1. 2. ve 3. sınıf) olmak üzere haftalık 30 saat ders okutulmaktadır (MEB Ders Çizelgesi, 2015) Almanya'da ise almanca, Hayat Bilgisi (sachunterricht), matematik, din bilgisi, beden eğitimi, müzik, resim-iş, anadil dersleri (yabancı öğrenciler için) ve tiyatro dersleri yer almaktadır. Haftalık ders saati de toplam 27 saattir.

İlkokulda ölçme ve değerlendirme. Türkiye'de ilkokul 1, 2 ve 3. sınıflarda öğrencilerin başarısı; gelişim düzeyleri dikkate alınarak öğretmen rehberliğinde gerçekleştirilen ders etkinliklerine katılımları ile öğretim programlarında belirtilen ölçme ve değerlendirme ilkelerine göre tespit edilir. Karnede "çok iyi”, "iyi” ve "geliştirilmeli" şeklinde gösterilir (Karabacak \& Öztunç, 2014). İlkokul 4. sınıfta ise öğrenci başarısı; sınavlar ile ders etkinliklerine katılım çalışmalarından alınan puanlara göre değerlendirilir. Almanya-Hamburg'da ise 2006'da kurulan IFBM (Institut für Bildungsmonitoring) daha iyi ve başarılı bir eğitim ortamı için okulları değerlendirme amacıyla kurulmuştur (CEDEFOP, 2011). İlk iki yıl birçok ders tek bir öğretmenle 
yapılır. 3. yıldan itibaren branş öğretmenleri ders vermeye başlar (İkizer, 2004). Dolayısıyla 1. ve 2. sinıfta sadece gözlemsel değerlendirme yapılarak, 3. ve 4. sınıfta ise yazılı ve sözlü değerlendirme yapılarak notlandırılmaktadır.

Türkiye ve Almanya- Hamburg eyaletinde okutulan Hayat Bilgisi dersi arasındaki benzerlik ve farklılıklar nelerdir?

Hayat Bilgisi dersinin tarihsel süreci açısından benzerlik ve farklılıklar. İlk kez 1869 yılında Saffet Paşa'nın Maarif Nazırlığı döneminde okutulmaya başlanan Hayat Bilgisi dersi, Cumhuriyet dönemi müfredatlarının tamamında da varlığını korumuştur (Başar, 2004; Binbaşıoğlu, 2003; Deringil, 2007; Kodaman, 1991). Cumhuriyetin ilanından günümüze Hayat Bilgisi öğretim müfredatları dönemin ihtiyaç ve beklentilerine uygun olarak zaman zaman değiştirilmiştir. Bu değişiklikler sırasıyla 1924 (Eşya Dersi), 1926, 1936, 1948, 1968, 1998 (Şahin, 2009) 2005, 2009, 2013 ve 2015'de gerçekleştirilmiştir. Almanya'da ise "Sachunterricht" 1920'lerde Weimar İlkokul Reformu ile başlamıştır. 1923 Eduard Spranger "Heimat" 1 ev olarak tanımlamış ve genel çalışmalar ve ev metaforunu kullanarak açıklamıştır (Weber, 2003). Ancak ilk olarak "Sachunterricht" ifadesi Alman eğitim sistemi için önemli olan "Strukturplan für das deutsche Bildungswesen” (1970) belgesinde yer almıştır. Günümüzde en son 2011 y1lında hazırlanan "Sachunterricht" programı kullanılmaktadır.

Hayat Bilgisi dersinin amacı açısından benzerlik ve farklılıkları. Türkiye'de bu derste çocuğa içinde bulunduğu doğal ve toplumsal çevre inceletilerek; kendini tanıma, çevreyi ve çevrede meydana gelen olayları anlama, daha iyi yaşama yollarını bulma, çevredeki eşyaların yerlerini ve bunların nasıl kullanılacağını bilme, Atatürk'ü tanıma, bireyin yakın çevresi ile ilgili günlük olaylara ilgi duyma, toplu yaşamın önemini kavrama, toplumun istediği davranışları gösterme, sağlıklı ve düzenli yaşama alışkanlıklarını kazanma gibi bireyin yaşadığı çevreyi daha iyi tanıması ve bu çevre ile uyumlu biçimde yaşayabilmesi için gerekli bilgi ve alışkanlıkların kazandırılmasına çalışılır (Hayat Bilgisi Öğretim Programı, 2015). Almanya- Hamburg'da okutulan Sachunterricht dersinin amacı ise öğrencilerin içinde bulundukları sosyal ve doğal ortamın temellerini anlamalarına yardımcı olmaktır. $\mathrm{Bu}$ süreç öğrenci deneyimlerini esas alan bir yaklaşımla kazandırılmaya çalışılmaktadır (Sachunterricht Grundschule, 2011).

Hayat Bilgisi dersinin yapısı açısından benzerlik ve farklııklar. Türkiye'de 2009 yılında hazırlanan Hayat Bilgisi dersi birey, toplum ve doğa öğrenme alanları çerçevesinde yapılandırılırken 2015 yılında yapılan yeni düzenlemede öğrenme alanı belirtilmemiştir (Aykaç: 2011; Tay \& Baş: 2015). Ayrıca 2009 programının tematik anlayışının 2015'te olmadığı ve bu yönü ile 2015 programında tematik anlayıştan vazgeçildiği söylenebilir. 2015 programında yer alan ünite temelli yaklaşımın ise önceki programlarda da uygulandığı görülebilir (Kocaoluk \& Kocaoluk, 1998; MEB, 2009; Tay \& Baş, 2015). 2015 Hayat Bilgisi Öğretim Programı'nda yer alan üniteler Şekil 1'de yer almaktadır. 
Şekil 1. Hayat Bilgisi Dersinin Üniteleri

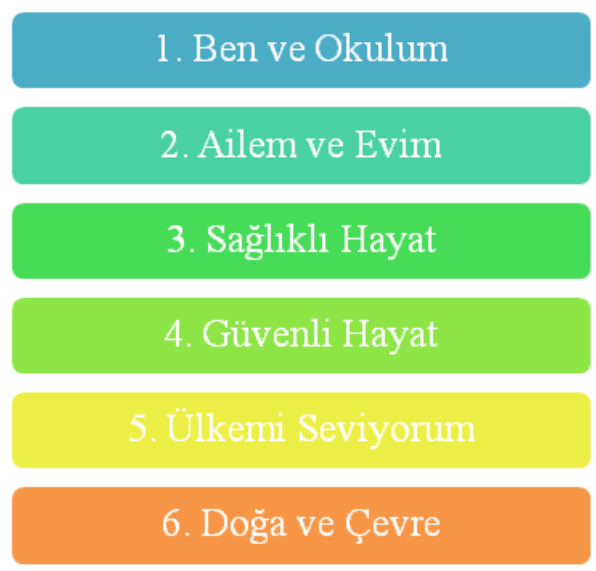

Uyarlandı̆̆ yayın. (Hayat Bilgisi Öğretim Programı, 2015).

Şekil 1 incelendiğinde Hayat Bilgisi dersinin birçok farklı disiplini barındıran bir ders olma özelliğini devam ettirdiği söylenebilir. Almanya-Hamburg'da da bu dersin sadece tek bir konu içermeyen; sosyal, sosyo-kültürel, ekonomi, biyoloji, cinsel eğitim, tarih, coğrafya ve güvenlik eğitimini kapsayan bir yapısı vardır (Reinhoffer, 2000). Farklı disiplinlerle bağdaştırılan bu ders ile ilgili tanımlar incelendiğinde dersin içeriğinde sadece sosyal bilimlerin ya da Fen Bilimlerinin yer almadığ disipline vurgu yapıldığg görülmektedir (Reinhoffer, 2000).

Şekil 2. Sachunterricht dersinin temaları

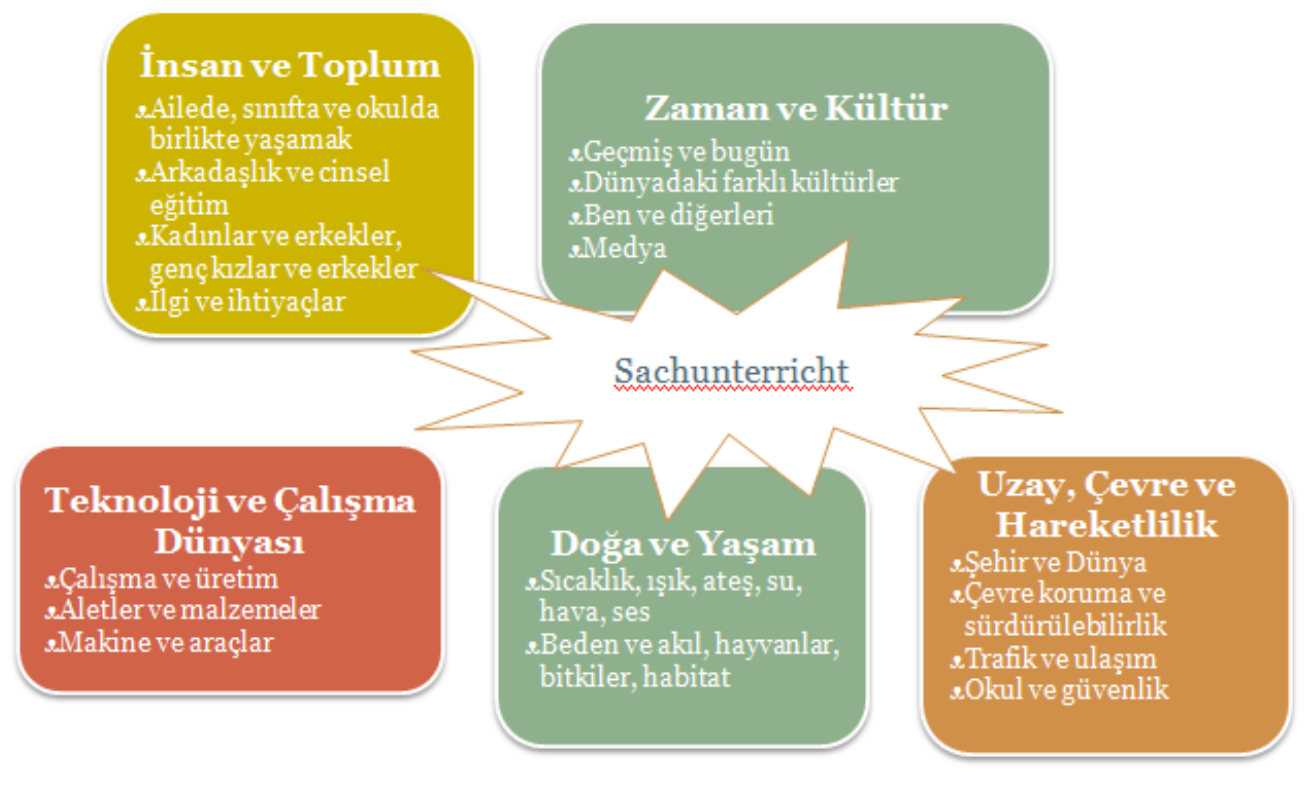

Uyarlandı̆̆g yayın. http://www.froebelschule-moitzfeld.de/sachunterricht.aspx

Sachunterricht dersinin temaları incelendiğinde Şekil 2'de de görüldüğü gibi birçok farklı disiplini bir arada barındıran bir yapısı olduğu görülmektedir. 
Hayat Bilgisi dersinin haftalık ders saati açısından benzerlik ve farklılıklar. Türkiye'de 4 y1llık bir dönemi kapsayan süreçte Hayat Bilgisi dersi 1. ve 2. sınıfta 4'er saat, 3. sinıfta ise 3 saat olarak verilirken 4. sinifta okutulmamaktadir. Almanya Hamburg'da ise 4 yıllık ilkokul eğitiminin 1. sinıfında 3 saat, 2, 3 ve 4. sinıfta 4'er saat olarak okutulmaktadır. Ders saatleri Tablo 2'de yer almaktadır.

Tablo 2

Türkiye ve Almanya- Hamburg Hayat Bilgisi Ders Saatleri

\begin{tabular}{lcccc}
\hline & 1.Sinıf & 2.Sinıf & 3. Sinıf & 4.Sinıf \\
\hline Türkiye & $\mathbf{4}$ & $\mathbf{4}$ & $\mathbf{3}$ & - \\
\hline Almanya-Hamburg & $\mathbf{3}$ & $\mathbf{4}$ & $\mathbf{4}$ & $\mathbf{4}$ \\
\hline
\end{tabular}

Tablo 2 incelendiğinde Hayat Bilgisi dersinin Türkiye'de ilk üç yıl Almanya Hamburg'da ise 4 yıl boyunca okutulduğu söylenebilir. Ülkemizde sınıf ilerledikçe ders saati azalma gösterirken Almanya Hamburg'da ise ilk sınıf itibari ile artarak devam etmektedir.

Hayat Bilgisi dersinin öğrenme alanları açısından benzerlik ve farklılıklar. Türkiye'de Hayat Bilgisi dersinin öğrenme alanları birey, doğa ve toplum olarak belirtilmiştir (Hayat Bilgisi Öğretim Programı, 2009). Ancak 2015 programı incelendiğinde herhangi bir öğrenme alanı vurgusu yapılmadığı görülmektedir (Hayat Bilgisi Öğretim Programı, 2015). Almanya- Hamburg Bildungsplan Grundschule Sachunterricht (2011) programı incelendiğinde ise 5 öğrenme alanı göze çarpmaktadır. Öğrenme alanları Şekil 3’te gösterilmektedir.

Şekil 3. Öğrenme Alanları

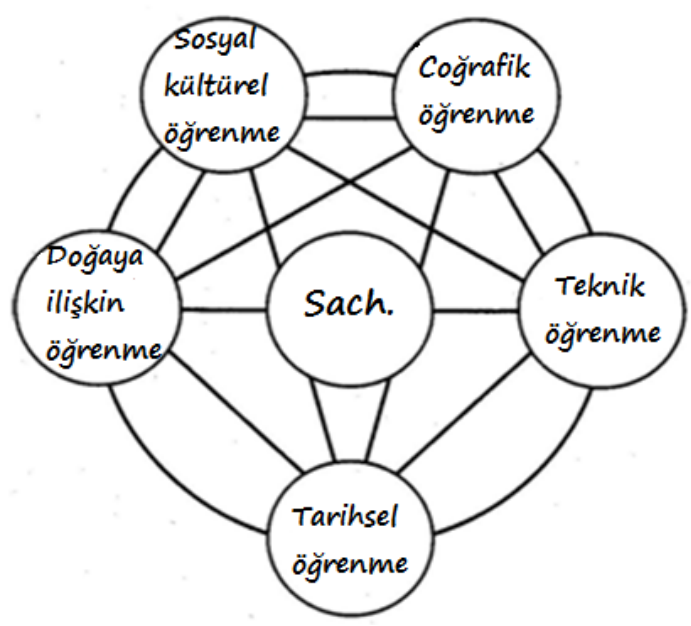

Uyarlandiğg yayın.

http://www.erdkunde-sonderschule.de/Begruendung/FachdidaktikSachkunde.html

Şekil 3 'te yer alan öğrenme alanları şöyle açıklanabilir: Sosyal kültürel öğrenme, çocuklar için erişilebilir birlikte yaşayan insanların deneyimleri ile sosyal ve kültürel bilimleri temel alan yöntemler ve içerik arasındaki alanı kapsar. Toplumda insanlar bir 
arada yaşarlar. Toplumda farklı politik, kültürel, ekonomik, fiziksel ve etnik koşullardaki farklılıkları doğal görmek, bu farklılıklarla başa çıkmayı daha kolay hale getirmektedir. Coğrafik Öğrenme, içlerinde bulundukları dünyayı, evreni, uzayı ve gezegenleri öğrenmeyi temel alır. Bu alana ilişkin öğrenme, çocuklar için erişilebilir bir çevrede deneyimleyebileceği bir yapıyı önemser. Doğaya ilişkin öğrenme, çocukların deneyimlerine yakın çevreyi anlayabilmeleri ve bilimi temel alan yöntem ve teknikler arasındaki alanı kapsar. Çocukların doğaya karşı sorumlu hissetmeleri sağlanabilir ve biyolojik, fiziksel ve kimyasal bağdaşımı doğada tecrübe edebilirler. Teknik öğrenme, teknoloji ile iyi ilişsiler kuran ve çocukların deneyimlerine dayanan teknolojiye bakış açısını temel alır. Teknoloji hayatımızın her alanını etkilemektedir. Yaşam standartlarımızı yükseltse de hayatımızı yıkma potansiyeline de sahiptir. Bu anlamda teknolojinin gelecekte insan hayatına en yüksek oranda fayda sağlayacak düzeye gelmesinin önemi konusunda farkındalık yaratır. Tarihsel öğrenme, beşeri bilimleri temel alır ve çocukların deneyimlerinde değişiklik yapabilmelerini sağlar. Yaşam koşulları çocuklara hazır olarak sunulur. "Sachunterricht" dersinin tarihsel perspektifi içinde bulundukları topluma karşı sorumlu olmalarını, yaşam koşullarının değişebilir ve geliştirilebilir olduğunu sağlamak üzerine kuruludur (Sachunterricht Grundschule, 2011).

Hayat Bilgisi dersinde kazandırılması hedeflenen beceriler açısından benzerlik ve farklılıklar. Türkiye'de Hayat Bilgisi dersinde kazandırılması hedeflenen beceriler: "araştırma, iş birliği, mekânı algılama, bilgi ve iletişim teknolojilerini kullanma, karar verme, öz yönetim, değişim ve sürekliliği algılama, kaynakların kullanımı, millî ve kültürel değerleri tanıma, dengeli beslenme, kendini koruma, sağlığını koruma, doğayı koruma, kendini tanıma, sorun çözme, girişimcilik, kişisel bakım, sosyal katılım, gözlem, kurallara uyma, zaman yönetimi” olarak belirlenmiştir (Hayat Bilgisi Öğretim Programı, 2015).

Almanya- Hamburg' da ise «Sachunterricht» dersinde kazandırılması hedeflenen beceriler 4 başlık altında toplanmıştır. Bu beceriler şöyle açıklanabilir (Sachunterricht Grundschule, 2011):

1. Dönüş̧ürülebilir Beceriler: Öğrencilerin hayatlarında işlevsel olarak kullanacaklarına inanılan becerilere odaklanmaktadır. $\mathrm{Bu}$ becerilerden ilki "benlik kavramı" ve "motivasyon"dur. Öğrencilerin kendilerine güvenmesini ama aynı zamanda da eleştirebilmesini temel alır. Bir diğer dönüştürülebilir beceri olarak "sosyal beceriler" ve "öğrenme becerileri” ne odaklanmaktadır. Bu alanlarda öğrencilerin gelişim düzeylerini dikkate alan öğretmenler teşvik edilmektedir.

2. Eğitim Dili Becerileri: Başarılı bir öğrenme için temel bir gereksinimdir. Çünkü öğretim dili gündelik dilden daha farklı bir yapıya sahiptir. Bu anlamda ana dili Almanca olmayan öğrenciler için ikinci zorunlu dil olarak Almancanın öğretilmesi söz konusudur. Dil öğretiminde kademeli ve sistematik bir süreç izlenmektedir. Ayrıca günlük dil ve eğitim dili arasındaki farklara dikkat çekilmekte, süreç buna göre yapilandırılmaktadir.

3. Özelleşmiş Beceriler: Sosyal ve doğal çevreyi deneyimlemek, demokratik bir toplumda birlikte yaşayabilmek tarihsel bilincin gelişimini teşvik etmek; aile öyküleri, kendi deneyimlerini referans alarak dün, bugün, yarın bilinci kazandırmak, coğrafi bakış açısında mekansal algılama ve yön duygusu kazandırmak, bilimsel bakış açısı altında 
gözlem, açıklama gibi becerilerini geliştirmek, şüphe duymasını ve kanıt temelli öğrenme bilincini kazandırmak, teknik açıdan teknoloji kullanımını geliştirmek.

4. Didaktik Illkeler: "Sachunterricht"i Öğrenme Becerileri: Öğrencilerin karmaşık becerileri çözümleyebilecek, onları etkin kılacak ve sosyal çevreleri ile mücadele edebilecek uygulamaları içermektedir. Bu uygulamalar şöyle sıralanabilir;

1. Gerekli bilgilere ulaşabilme becerisine sahip olmak,

2. Gerekli bilgileri elde etmek,

3. "Sachunterricht" ile ilgili merkez ilişkileri belirlemek,

4. Uygun eylem adımlarını düşünmek ve planlamak,

5. Yaratıcı çözümleri test etmek,

6. Uygun eylem kararları almak,

7. Mevcut bilgi, beceri ve yetenekleri kullanmak,

8. Uygun kriterlerle kendi eyleminin sonuçlarını değerlendirmek.

Hayat Bilgisi dersinde ölçme ve değerlendirme açısından benzerlik ve farklılıklar. Türkiye'de 2009'da hazırlanan Hayat Bilgisi Öğretim Programı değerlendirme teknikleri; "arkadaşlarının oyunlarına katılırken, onlarla oyun kurarken ve oynarken uygun davranışlarda bulunup bulunmadığı" genellikle gözlemlerle, "her canlının bir yuvaya ihtiyacının olduğunu kavraması ve canlıların yuvalarını birbirinden ayırt etmesi" ise performans ödevi ile, kullanma, yorumlama gibi üst düzey becerileri ölçmede açık uçlu sorular gibi örneklerle açıklanmıştır.

2015 Hayat Bilgisi Öğretim Programı incelendiğinde ise öğretmen, öğrenciler üzerinde bir ölçme ve değerlendirme baskısı oluşmaması amacıyla etkinliklerin ve gözlemlerin kullanılmasına öncelik vermelidir. Sınıf içinde yapılacak çeşitli etkinliklerde gösterdiği performans gözlemlenerek değerlendirilir. Ayrıca öğrencilerin gelişimini süreç içerisinde izlemeli, öğrenme eksikliklerini ve güçlüklerini belirleyerek eksiklikleri gidermek veya öğrenmeyi geliştirmek amacıyla düzenlemeler yapmalıdır (MEB, 2015).

Ayrıca derse yönelik etkinliklere ve değerlendirme örneklerine yer verilmiştir. Ancak 2015 programı incelendiğinde ölçme ve değerlendirme formalarına ve örneklere yer verilmediği görülmektedir. Her iki programda da değerlendirme anlayışlarının hem ürünü hem de süreci ölçmeye yönelik olduğu anlaşılmaktadır (Tay \& Baş, 2015).

Almanya'da ise öncelikle öğretmenin görevlerinden biri olarak görülen diyalog ile öğrenci, veli ve öğretmen iletişiminde sorumluluğu öğretmene yüklediği görülmektedir. $\mathrm{Bu}$ diyaloglar ile öğrencinin akademik ve sosyal gelişimini birlikte değerlendirme ve karar verme gerçekleşmektedir. Bildungsplan Grundschule Sachunterricht (2011) incelendiğinde değerlendirme "öğrenmeyi değerlendirme" ve "öğrenme çıktılarını değerlendirme” olarak iki ayrı bölümde aktarılmıştır: 
Tablo 3

Sachunterricht Değerlendirme Yaklaşımı

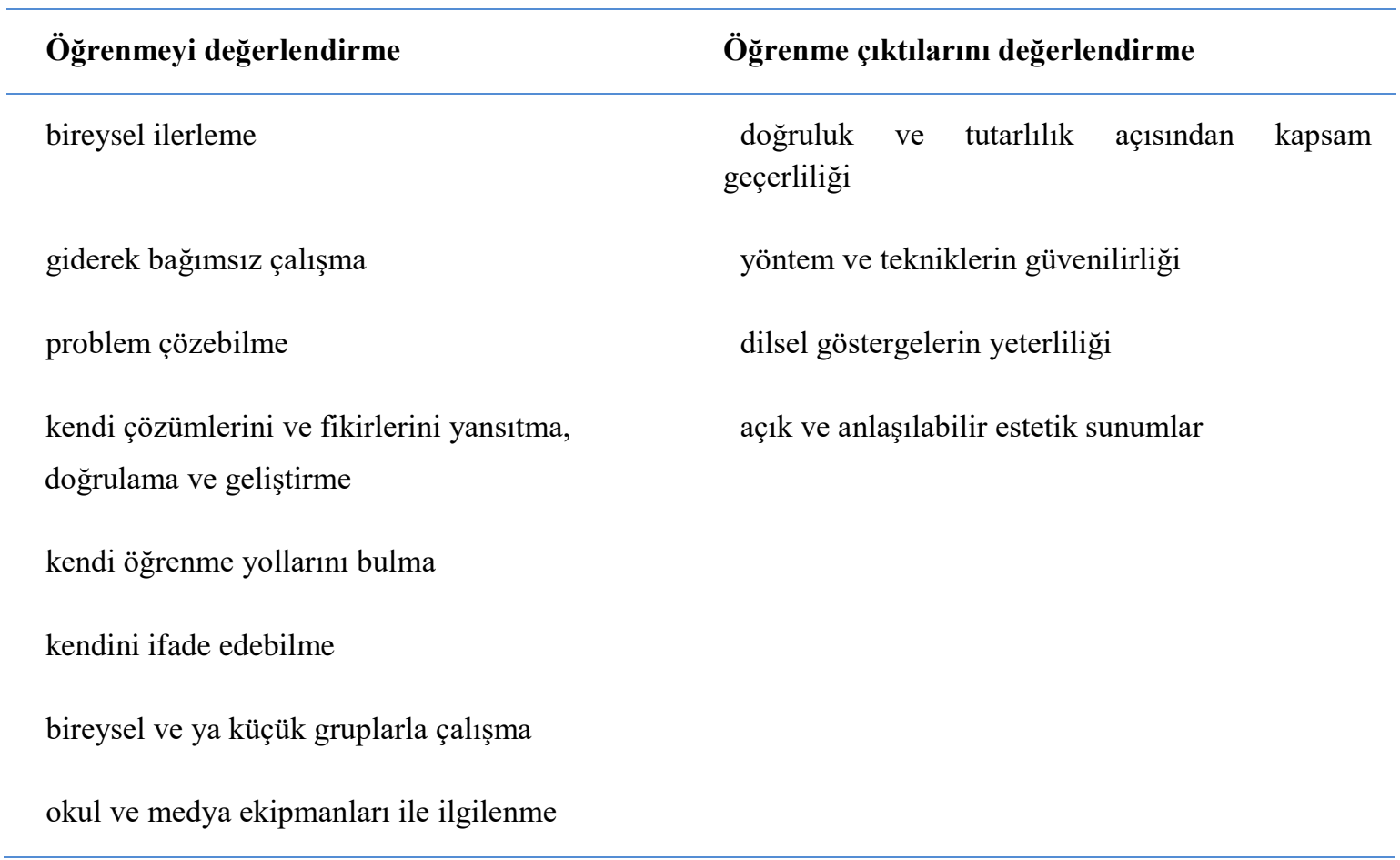

Uyarlandığı Yayın. Bildungsplan Grundschule Sachunterricht Programı (2011)

Tablo 3 incelendiğinde hem süreci hem de ürünü değerlendirme yaklaşımını benimsedikleri; ölçme ürünlerinin geçerlik ve güvenilirliğini önemsedikleri söylenebilir. $\mathrm{Bu}$ bağlamda performans değerlendirme teknikleri şu şekilde belirlenmiştir: Davranışlar (bağımsız ve işbirliği ile çalışma, grup çalışması yürütebilme, derse katılım vb.), sözlü çalışmalar (sözlü sunumlar, kendi çözüm yollarını sunma vb.), uygulamalar (model ve poster hazırlama, çizim yapma, matematiksel seyahat günlükleri, portfolyo, bağımsız araştırmalar yapma) ve son olarak yazılı çalışmalar (yazılı alıştırmalar, araştırma defterleri, çalışma kitapları, portfolyo).

\section{Sonuç ve Tartışma}

Ülkeler eğitimlerini bir sistem dâhilinde yürütürler. Bu sistemler her ülkenin kendi ideolojisine uygun bir yapıdadır ve eğitim sistemine doğrudan etki ederler (Çeltikci, 2013). İki ülkede okutulan Hayat Bilgisi dersi çocuğu hayata hazırlama basamağı olarak görülmekte ülkemizde Fen Bilimleri ve Sosyal Bilgiler derslerine temel oluşturmaktadır. Ülkemizde 2015 programıyla birlikte bu dersin şekli değiştirilmekte, önemi azaltılmakta ve branşlaşmaya gidilmektedir.

Karş1laştırılan iki ülkenin önce genel eğitim sistemleri üzerinde durulmuş, bu durum açıklandıktan sonra Hayat Bilgisi dersi karşılaştırılmaya başlanmıştır. İncelenen başlıklar altında genel hatlarıyla eğitim sistemleri daha sonra dersin; tarihsel süreci, amacı ve vizyonu, haftalık ders saati ve içeriği, dersin yapısı, öğrenme alanları, kazandırılması hedeflenen beceriler ve ölçme ve değerlendirme açısından benzerlik ve farklılıklar üzerinde dikkatle durulmuştur.

Türkiye ve Almanya- Hamburg eyaletinde ilkokul eğitim sistemleri arasındaki benzerlik ve farklılıklar şöyledir: Okula başlama yaşı iki ülkede de 6 yaşını tamamlayan 
çocuklar için zorunlu iken ülkemizde 66 ayını dolduran çocuklar ailenin isteği ile okula başlatılabilmektedir. Ülkemizde 4+4+4, Almanya-Hamburg'da 4+5+3 olmak üzere 12 yıllık zorunlu eğitim uygulanmaktadır. Okul seçimi ve kıyafet yönetmeliği her iki ülkede benzer uygulamalarla yürütülmektedir. Eğitim desteği ve finansman boyutunda ise Türkiye'de Milli Eğitim Bakanlığı, Almanya-Hamburg'da ise federal yönetim tarafından karşılanmaktadır. İlkokulun amaçları açısından benzerlik gösteren bir yapı olduğu söylenebilir. Ülkemizde iyi bir Türk vatandaşı olma vurgusu yapıllyorken Almanya-Hamburg'da öğrenme yeteneğini geliştirmek ve sosyalleşmesini sağlama noktasına vurgu yapılmıştır. İki ülkede de okutulan dersler açısından benzerlik olduğu söylenebilir. Farklı olarak ülkemizde Fen Bilimleri, trafik güvenliği, insan hakları, yurttaşlık ve demokrasi, serbest etkinlikler dersi yer almaktadır. Ülkemizden farklı olarak Almanya-Hamburg'da ise tiyatro dersi zorunlu olarak okutulmaktadır.

Türkiye ve Almanya-Hamburg eyaletinde ilkokul eğitim sistemleri arasındaki benzerlik ve farklılıklar şu şekilde ifade edilebilir: İlkokulda ölçme ve değerlendirme açısından iki ülke arasında benzer uygulamaların olduğu söylenebilir. Ancak ülkemizde 1, 2 ve 3. sınıfta değerlendirme "çok iyi”, "iyi” ve "geliştirmeli" şeklinde, 4. sınıfta yazılı ve sözlü sınavlarla yapılmaktadır. Almanya-Hamburg'da ise önemli olan davranış kazandırma olduğu için 1 . ve 2. sınıfta notlandırma yapılmamakta, 3. ve 4. sınıfta ise sözlü, yazılı değerlendirme ve yönlendirme başlamaktadır.

Hayat Bilgisi dersinin tarihsel süreci ülkemizde Almanya- Hamburg'dan yaklaşık olarak 50 yı önce başlamaktadır. Hayat Bilgisi dersinin amacı ülkemizde daha ayrıntılı ve kapsamlı bir şekilde listelenirken Almanya- Hamburg'da daha sade ve net ifadelerle belirtilmiştir. Hayat Bilgisi dersinin yapısı incelendiğinde ülkemizde ünitelerden, Almanya Hamburg'da ise temalardan oluşan bir yapıya sahip olduğu söylenebilir. Hayat Bilgisi dersi ülkemizde ilk üç yılda 4, 3 ve 3'er saat, Almanya Hamburg'da ise dört yıl boyunca 3, 4, 4 ve 4'er saat okutulmaktadır. Hayat Bilgisi dersinin öğrenme alanları ülkemizde 2009 programında birey, doğa, toplum olarak belirtilirken 2015 programında herhangi bir öğrenme alanı vurgusu yapılmamıştır. Türkiye'de Hayat Bilgisi dersinde kazandırılması hedeflenen 22 beceri bulunmakta iken Almanya-Hamburg'da dönüştürülebilir, eğitimi dili becerileri, özelleşmiş beceriler ve Sachunterrricht'i öğrenme becerileri olmak üzere 4 ayrı başlık altında sunulmuştur. Hayat Bilgisi dersinde ölçme ve değerlendirme boyutunda öğretmenlere öğrenciler üzerinde bir ölçme ve değerlendirme baskısı oluşmaması amacıyla etkinlikler ve gözlemleri kullanması önerilmiştir. Öğretmenin süreci izlemesi ve eksikleri giderme konusunda titiz davranması beklenmektedir. Almanya- Hamburg'da ise performans değerlendirme alanları ve yöntemler listelenerek öğretmenlere sunulmuştur.

Hayat Bilgisi dersinin karşılaştırıldığı bu tür çalışma alan yazında yer almamakla birlikte farklı başlıklar altında karşılaştırmalı çalışmalar yapıldı̆̆ı görülmektedir. Örneğin Pamuk ve Pamuk (2016)'un yaptığı Almanya ve Türkiye'deki Hayat Bilgisi ders kitaplarındaki konuların karşılaştırıldı̆̆ı çalışmasında Almanya'da bilgiyi somutlaştırmaya yönelik görsellerin daha yoğun olarak kullanıldığı ortaya konulmuştur. Yine Tural ve Diğerleri (2017) tarafından yapılan "Türkiye ve Almanya'daki Hayat Bilgisi Ders Kitaplarının Resim Metin İlişkileri ve Kullanımları Bakımından Karşılaştırılması" isimli çalışmalarında da bir önceki çalışmayı destekleyici sonuçlara ulaşılmıştır. 
Sonuç olarak Hayat Bilgisi dersi iki ülke arasında ders isimleri birbirine benzer bir yapı sergiliyor olsa da farklı koşullarda ve içerikte aktarılmaya çalışılmaktadır. Araştırmacılar tarafından belirlenen başlıklar altında benzerlik ve farklılıklar ortaya konulmaya çalışılmıştır. Gelecekteki çalışmalarda;

- İki ülkede de Hayat Bilgisi dersinin tarihsel gelişimi daha detaylı bir şekilde ele alınarak felsefesi ortaya konabilir.

- İki ülkede de bu dersi yürüten öğretmenler veya dersi alan öğrencilerle görüşerek uygulamaya yönelik farklar ortaya konabilir.

- Türkiye'deki durumu daha geniş bir perspektiften görebilmek için Hayat Bilgisi dersine benzer bir ders olan ülkeler incelenerek farklı başlıklar altında karşılaştırmalar yapılabilir. 


\section{Summary}

Purpose and Significance: The purpose of this study is to compare the current curricula of the life science courses implemented in Turkey and Germany-Hamburg to reveal the similarities and differences between them. Germany-Hamburg was chosen for comparison because the life science course, which is called social sciences course in many countries, taught there has a similar structure to the one taught in Turkey. The common aspects of these two countries make the conclusion more meaningful. Literature review was conducted first to determine the relevant criteria for the comparison between the two countries. In this way, the official documents of both countries were reviewed.

Method: In this search it is used the horizontal and descriptive approach as a method. For this purpose it is compared similarities and differences by examining the relevant literature in identifying approach; it is also discussed all dimensions in based on the obtained data, the similarities and differences between the countries were identified with regard to school starting age and compulsory education structure, educational administration and financing, school choice, dress and educational support, the goals of elementary school, the courses taught, and assessment and evaluation. Then the curricula implemented in the two countries were compared in terms of acceptance date, course content, mission/vision, the prescribed skills or competencies, and assessment and evaluation.

Results: The findings indicated similarities between the countries in terms of elementary school starting age, compulsory education structure, school choice, and dress code and differences in terms of educational administration and financing. As to the structure of the life science course, similarities and differences were determined in terms of weekly course hour, the goals of the course, the skills intended to be taught, and assessment and evaluation.

Discussion and Conclusions: The similarities and differences between Turkey and Germany-Hamburg city are like these: the age of starting school is an obligatory for the children who completed 6 years, the same at the both countries; but in our country the children who completed 66 months can start the school with the allowance of their parents. The obligatory education for 12 years is performed in our country is as $4+4+4$ and in Germany-Hamburg is $4+5+3$. The school choice and dress code are applied with the similar applications at the both countries. The financial way and education supports are supplied by the National Education Ministry in Turkey and by the Federal Direction in Germany-Hamburg. It can be said that the primary school is a structure that can show the similarities in terms of its aims. While being a good Turkish citizen is emphasized in our country, the point of improving learning skill and socializing are emphasized in Germany-Hamburg. It can be said that there are similarities in terms of the lessons at the both countries. As a difference in our country; there are sciences, traffic security, human rights, citizenship, democracy and free activities. In Germany-Hamburg the drama lesson is educated as an obligatory lesson as well. The similarities and differences in Turkey and Germany-Hamburg city between primary education systems can be 
expressed like this: there are similar applications between the both countries in terms of measurement and evaluation, but in our country the evaluation is like "very good", "good" and "must be improved" at the 1st, 2nd and 3rd classes and it is applied by oral and written exams at the 4th class. On the other hand in Germany-Hamburg there is no giving mark because of the important thing is gaining behavior at the 1st and 2nd classes. The oral and written evaluation and direction start at the $3 \mathrm{rd}$ and 4 th classes. 


\section{Kaynakça}

Aykaç, N. (2011). Hayat bilgisi dersi öğretim programında kullanılan yöntem ve tekniklerin öğretmen görüşlerine göre değerlendirilmesi (Sinop ili örneği). Kastamonu Ĕ̈itim Fakültesi Dergisi, 9(1), 113-126.

Bal, B., \& Başar, E. (2014). Finlandiya, Almanya, Singapur ve Türkiye'nin eğitim sistemleri açısından kademeler arası geçiş sistemlerinin karşılaştırılması. Çukurova Üniversitesi Türkoloji Makale Bilgi Sistemi, No: 18776, 1-24.

Başar, E. (2004). Milli Ĕgitim bakanlarının eğitim faaliyetleri (1920-1960). İstanbul: Milli Eğitim Basımevi.

Beutner, B., \& Medvedev, A. (2013). Hamburg'da okulu anlamak: Göçmen veliler için başvuru kitapçı̆̆ı. Erişim Tarihi: 05.03.2016

http://www.hamburg.de/contentblob/3989124/f01de53bb7682a99f365e2810b07d9f

9/data/elternratgeber-tuerkisch-29-5-

.pdf;jsessionid=027153D615F23098A8FB4CA435046F83.liveWorker2

Bildungsplan Grundschule Sachunterricht (2011). Erişim Tarihi: 05.02.2016.

http://www.hamburg.de/contentblob/2481914/25c3a10b03cc2be4003d7b6f9c43678

7/data/sachunterricht-

gs.pdf;jsessionid=7E11EB078F83CFF6BC5F36722FC11C79.liveWorker2

Binbaşıŏlu, C. (2003). Hayat bilgisi ögretimi. Ankara: Nobel Yayın Dağıtım.

European Centre for the Development of Vocational Training (CEDEFOB). (2011). Evaluation for improving student outcomes: messages for quality assurance policies. Luxemburg: Publications Office of the European Union.

Çeltikci, O. (2013). Türkiye Azerbaycan eğitim sistemlerinin karşılaştırılması üzerine bir inceleme. Bilim ve Kültür Uluslararası Kültür Araştırmaları Dergisi, 1(2), 4057.

Deringil, S. (2007). İktidarın sembolleri ve ideoloji: II. Abdülhamid dönemi (18761909). (G.Ç. Güven, Çev.), İstanbul: Yapı Kredi Yayınları.

Hamburg Eğitim Ataşeliği (2013). Hamburg ve Schleswig eğitim sistemi. Erişim Tarihi: 05.02.2016.

http://hamburg.meb.gov.tr/www/hamburg-ve-schleswig-egitim-sistemi/icerik/7

İkizer, İ. (2004). Almanya, Fransa ve Polonya'nın eğitim sistemlerine genel bir bakış. Universite ve Toplum Dergisi, 4(3), 8-24.

Kantos, Z. E. (2013). Federal Almanya Cumhuriyeti eğitim sistemi. A. Balcı (Ed.), Karşılaştırmalı eğitim sistemleri (ss. 49- 68). Ankara: Pegem Akademi.

Karabacak, K., \& Öztunç, M. (2014). Öğrenci karnelerinin aile görüşmeleri ile dağıtılması. Akademik Sosyal Araştırmalar Dergisi, 2(7), 287-300.

Kasapçopur, A. (2007). Avrupa Birliği ülkelerinde ĕgitim denetimi. MEB: Teftiş Kurulu Başkanlığı.

Kocaoluk, F., \& Kocaoluk, M. (1998). İlköğretim okulu programı. İstanbul: Kocaoluk Yayınevi.

Kodaman, B. (1991). Abdülhamid devri eğitim sistemi. Ankara: Türk Tarih Kurumu Basımevi. 
MEB (2009). İlkögretim hayat bilgisi dersi öğretim programı. Ankara: Talim ve Terbiye Kurumu.

MEB (2012). 12 yll zorunlu eğitim sorular ve cevaplar. Erişim Tarihi: 05.03.2016 http://www.meb.gov.tr/duyurular/duyurular2012/12Yil_Soru_Cevaplar.pdf

MEB (2015). İlköğretim kurumları (ilkokul ve ortaokul) haftalık ders çizelgesi. Erişim Tarihi: 06.03.2016 http://ikgm.meb.gov.tr/upload/TTK\%C3\%A7izelge.pdf.

MEB (2015). Illkokul hayat bilgisi dersi (1, 2 ve 3. Sinıflar) öğretim programı. Ankara: Talim ve Terbiye Kurumu.

Özmen, F., \& Yasan, T. (2007). Türk eğitim sisteminde denetim ve avrupa birliği ülkeleri ile karşılaştırılması. Doğu Anadolu Bölgesi Araştırmalar Dergisi, 6(1), 204-210.

Reinhoffer, B. (2000). Heimatkunde und sachunterricht im anfangsunterricht. Entwicklungen, stellenwert, tendenzen. Bad Heilbrunn: Klinkhardt.

Resmi Gazete (1973). Milli Ĕ̆itim Bakanlı̆̆ 1739 sayıl temel eğitim kanunu. No: 14574.

Resmi Gazete (2014). Millî Eğitim Bakanlı̆̆ı okul öncesi eğitim ve ilköğretim kurumlari yönetmeliği. No: 29072.

Sağlam, H. İ. (2015). Toplum, birey ve doğaya bütüncül bakış: Hayat bilgisi. M. Gültekin (Ed.), Hayat bilgisi öğretimi (ss. 1-14). Ankara: Nobel Yayınları.

Sincar, M., \& Özbek, M. (2011). Adrese dayalı nüfus kayıt sisteminin öğrenci kayıtlarında esas alınmasına ilişkin okul yöneticilerinin görüşleri. Eğitim ve İnsani Bilimler Dergisi: Teori ve Uygulama, 2(3), 29-52.

Şahin, M. (2009). Cumhuriyetin kuruluşundan günümüze Türkiye'de Hayat Bilgisi dersi programlarının gelişimi. Journal of International Social Research, 2(8), 402410.

Tay, B., \& Baş, M. (2016). 2009 ve 2015 yılı hayat bilgisi dersi öğretim programlarının karşılaştırılması. Bayburt Eğitim Fakültesi Dergisi, 10(2), 341-374.

Tural, A., Şahan, G., Işık, A. D., Özdemir, S., Uysal, H., \& Yı1maz, O. (2017). Türkiye ve Almanya'daki hayat bilgisi ders kitaplarının resim-metin ilişkileri ve kullanımları bakımından karşılaştııılması. Bartın Üniversitesi Eğitim Fakültesi Dergisi, 6(2), 770-782.

Türkoğlu, A. (1998). Karşılaştırmalı eğitim, dünya ülkelerinden örneklerle. Adana: Baki Kitabevi.

Pamuk, İ., \& Pamuk, A. (2016). Almanya'da sachunterricht ve Türkiye'de hayat bilgisi ders kitaplarında okulda demokrasi uygulamalarına örnek olarak sınıf başkanı seçimi. Cumhuriyet International Journal of Education, 5(2), 67-83.

Uygun, S., Ergen, G., \& Öztürk, İ. H. (2011). Türkiye, Almanya ve Fransa'da öğretmen eğitimi programlarında uygulama eğitiminin karşılaştırılması. İlköğretim Online, 10(2), 389-405.

Ültanır, G. (2000). Karşılaştırmalı eğitim bilimi. Ankara: Eylül Kitabevi.

Weber, B. (2003). Economic education in Germany. Journal of Social Science Education, 1(2), 1-16. 
cc) $(9)$ This is an Open Access article distributed under the terms of the Creative Commons license AttributionCC) No NC ND Commercial-NoDerivatives 4.0 International License. Consultation is possible at http://creativecommons.org/licenses/by-nc-nd/4.0/ 